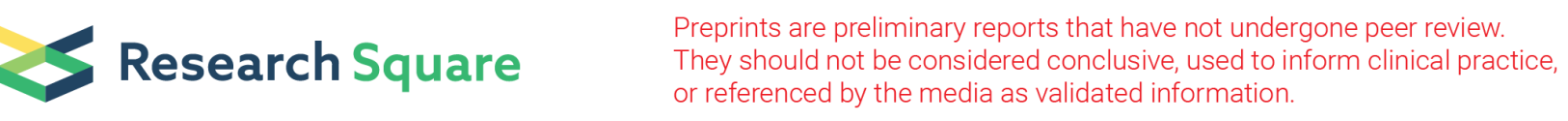

\title{
Physical Inactivity, and Its Association with Hypertension Among Employees in the District of Colombo
}

\author{
Anuji Upekshika Gamage ( $\nabla$ anujigamage@gmail.com ) \\ General Sir John Kotelawala Defence University \\ Rohini de Alwis Seneviratne \\ General Sir John Kotelawala Defence University
}

\section{Research Article}

Keywords: Physical-inactivity, Commuting-distance, hypertension, social-inequalities, employees

Posted Date: June 3rd, 2021

DOl: https://doi.org/10.21203/rs.3.rs-558775/v1

License: (c) (1) This work is licensed under a Creative Commons Attribution 4.0 International License. Read Full License

Version of Record: A version of this preprint was published at BMC Public Health on November 29th, 2021. See the published version at https://doi.org/10.1186/s12889-021-12013-y. 


\section{Abstract}

Background: Physical inactivity is a leading cause of morbidity and mortality and is a major public health problem. Insufficient activity is responsible for a large proportion of non-communicable diseases such as hypertension

Objectives: The purpose of this study was to assess socio-economic variations in physical activity and to measure the association between physical-inactivity and hypertension among government officials in Sri Lanka.

Methods: A cross-sectional study was carried out among 275 senior-officers(SOs) and 760 managerialassistants(MAs) aged 30-60 years and attached to Public Administration institutions in Colombo District in Sri Lanka. Physical-activity(PA) was gathered using the International Physical Activity Questionnaire(IPAQ) adopted and validated to the Sri Lankan context. Blood pressure(measured and classified using JNC-7 guidelines), and anthropometric indices were recorded. Energy utilization of all vigorous and moderated PA and walking was expressed as metabolic-equivalent-of-task(MET) min per week. A total MET score was calculated and categorized based on IPAQ guidelines.

Results: Socio-economic variations in PA levels were observed as $58.1 \%(n=158)$ SOs and $30.6 \%(n=226)$ MAs were involved in inadequate PA. Of the diagnosed hypertensives, $44.7 \%(n=106)$, and $49.4 \%(n=117)$ reported a low and moderate PA and considering non-hypertensives, 35.9\%( $n=278), 57.5 \%(n=445)$ reported a low and moderate activity levels respectively. After adjusting for potential confounding factors being physically inactive was associated with a higher risk of hypertension[Odds rate ratio(OR) $1.33[95 \%$ $\mathrm{Cl} 1.07,1,65]$, indicating that physical-inactivity increased the risk of hypertension by $30 \%$. The main modality of commuting to work for SOs(59\%) was private transport, and MAs $(64 \%)$ public transport Commuting distance was positively correlated $(p<0.05)$ with total transport MET among SOs and MAs. After adjusting, commuting distance of $>20 \mathrm{~km}$ was associated with lower odds of hypertension among SOs and MAs(OR=0.713; $95 \% \mathrm{Cl} 0.4$ to 1.3 ; and $\mathrm{OR}=0.63 ; 95 \% \mathrm{Cl} 0.46$ to 0.87$)$.

Conclusion: Despite the current knowledge that being physically active promotes health, the practice was different. Physical inactivity was associated with hypertension and prevalent among both SOs and MAs. Higher commuting distance is positively correlated with total transport MET and associated with lower odds of hypertension among SOs and MAs. Longitudinal studies are required to provide a causative association between physical inactivity and hypertension among these employees.

\section{Introduction}

Physical inactivity is a leading cause of death and therefor a major public health problem[1]. There is compelling evidence that physical inactivity is responsible for a large proportion of coronary heart disease and type II diabetes, and hypertension[2]. Physical inactivity led to $9 \%$ of premature deaths (5.3 million deaths) in $2008[3,4]$. Additionally, there are socio-economic variations observed in physical inactivity [5]. Recent World Health Organization guideline on physical activity recommends that adults 
should engage in at least 30 minutes of moderate-intensity physical activity for at least five days/ week[6]. There is epidemiological evidence that suggests a dose-dependent relationship between physical activity and hypertension [7].

Although physical inactivity is prevalent, studies on this is limited. However, baseline information of the prevalence of physical inactivity is important as this would guide policies and programme to address this. In a study that compared the worldwide variability of physical inactivity involving 51 countries in 2007 reported that overall, $17.7 \%$ were physically inactive. The same study reported that people living in urban areas were more inactive than rural areas [8]. Another study published in Lancet in 2018 reported that $27.5 \%$ of the $(95 \% \mathrm{Cl} 25 \%-32 \%)$ of adults are insufficiently physically active[9]. The same study reports that women are less active (31.7\%) compared to men (23.4\%). Considering Sri Lanka $7.5 \%$ of males' ad $14.1 \%$ females were physically inactive. Therefore by initiating programmes to reduce physical inactivity deaths can be averted[3].

When assessing physical activity (PA), there are four main dimensions that are of interest; the type of, the frequency, the duration, and the intensity of the PA [10]. The type of PA is referred to the different types of activities the subjects are engaged in. The frequency of PA activity refers to the number of sessions of physical activity per unit of time. The duration is the length of time spent in each activity session. Additionally, there are four main types of daily physical activity: occupation-related, transport-related, household-related, and leisure time-related[10,11]. The occupational activity involves activity at work and commuting to work. An occupational activity represents the greatest portion of daily time for most adults who are employed before retirement. Commuting to work is defined as regular travel between one's place of residence and place of work. It is believed that sedentary behavior associated with long-distance commuting hinders physical activity and is associated with ill health.

The development of questionnaire-based methods for assessing PA has paved the way to assess the amount and patterns of PA and also determine the relationship between PA and health-related outcomes. The International Physical Activity Questionnaire (IPAQ) was developed in Geneva in 1998 [10, 11]. Two IPAQ versions are available (a long version and a short version), and both versions are available in selfadministered or interviewer-administered forms. The reliability and validity of the IPAQ were established across 12 countries in 2000, including Sri Lanka [11]. The IPAQ assesses the PA in the last seven days. IPAQ assesses the energy expenditure of adults using a compendium of physical activities to estimate energy expenditure. The compendium was developed based on adult activities and can correctly estimate the employed population's physical activities [11].

Metabolic equivalent of task (MET) is a physiological measure expressing the energy cost (or calories) of physical activities. The total volume of physical activity can be quantified in MET-hours per day per week $[12,13]$. This is the total of all different activities performed during the assessment period expressed in MET equivalent and multiplied by all time spent in all activities. Considering the MET values, the type, and the frequency of the PA, the total volume can be categorized into insufficient/low, sufficient/ moderate, or vigorous/highly activity[12, 13]. 
This study aimed to measure the association between physical inactivity and hypertension and explore socio-economic variations in physical activity in government officials in Sri Lanka. By exploring the socioeconomic variations in physical inactivity among the study population, we aim to fill the knowledge gap related to physical inactivity, enabling policymakers and clinicians to make better evidence-informed decisions and develop an equitable delivery of interventions, especially at the workplace.

\section{Methods}

\section{Participants}

A descriptive cross-sectional study was conducted among senior officers and managerial assistants attached to public administration offices in the Colombo District [14]. In this district, there are 23 such offices. The total number of senior officers (SOs) and managerial assistants (MAs) attached to the institutions were 358 and 1231, respectively. The study population comprising full-time, permanent SOs and MAs between the ages of 30 to 60 years and employed for at least one year or more in a similar government institution in a similar cadre post were selected for the study. Officers on maternity or other extended leave and officers on prolonged (more than one month) steroid therapy confirmed by documented evidence were excluded from the study[14].

Sample size calculation to detect the prevalence of hypertension was done assuming the prevalence of hypertension among adults was $20 \%, 95 \%$ confidence interval, and a precision of 0.05 using the formula to detect a population proportion. Ten percent was added to account for nonresponse. Sample size calculation was done separately for SOs and MAs since they were regarded as 2 study populations. Thus, the final calculated sample size for SOs and MAs was 275 and 760, respectively. A stratified simple random sampling technique was used to select the SOs and MAs. Stratification was done according to 23 institutions they are attached to, and the number needed to select from each institution was decided according to probability proportionate to the size (PPS). The required number of SOs and MAs from each institution was selected randomly based on the number allocated to each institution according to PPS. The latest updated version of the payroll was used as the sampling frame for sampling, and the completeness was checked with an institutional name list before use. A unique ID number was given to all the eligible officers. Computer-generated random numbers were used to identify the study participants. The identified officers were met face to face and invited to participate in the study. The study population that was recruited, sampling procedure, and phases of the study are given in Figure 1[15].

Ethical clearance was obtained from the Ethical Review Board of Faculty of Medicine, University of Colombo. Permission and consent were obtained from the Ministry of Public Administration and Home Affairs and all heads of institutions before the commencement of the study. Written informed consent was obtained from all respondents after informing the following in the information sheet: the purpose, the objectives, and benefits to the occupational group by conducting this study. 
A self-administered questionnaire (SAQ) was used to gather information, which consisted of 3 broad components: sociodemographic characteristics; work-related information, which included validated IPAQ; and lifestyle-related correlates of hypertension. In addition to the SAQ, a data collection form was used to record blood pressure (BP), anthropometric measurements, fasting blood sugar values, and record information on the participants past medical history and drug history. To assess test-retest reliability, $10 \%$ of the questionnaires were readministered to randomly selected study participants 2 weeks after the initial data collection.

\section{Measures}

Blood Pressure. The BP measurements were done based on the American Heart Association BP measurement recommendations, which reduced the intra-observer error of BP measurements $[16,17]$. The principal investigator carried out all BP measurements. Participants were allowed to sit for 5 minutes before measuring BP. The participants were asked to refrain from smoking or ingesting caffeine during the 30 minutes preceding the BP measurement. A cuff with a bladder that is $12-13 \mathrm{~cm} 35 \mathrm{~cm}$ in size with a larger bladder for fat arms was used. The bladder within the cuff will encircle at least $80 \%$ of the arm. The cuff was placed at the heart level of the patient. The disappearance of Phase V Korotkoff sounds was used to measure the diastolic BP. Two BP readings were obtained separated by 1 minute. The average of these two values was taken.

An additional reading was taken and averaged when the first two readings differed by more than $5 \mathrm{~mm}$ $\mathrm{Hg}$. Classification of hypertension was done based on the classification of the Joint National Committee on Prevention, Detection, Evaluation, and Treatment of High Blood Pressure (JNC-7)[18]. A person was considered hypertensive if he/she was an already diagnosed case of hypertension and/or on treatment or with a current systolic BP of ${ }^{3} 140 \mathrm{~mm} \mathrm{Hg}$ or diastolic BP ${ }^{3} 90 \mathrm{~mm} \mathrm{Hg}$ (JNC-7 criteria)[18].

Physical Inactivity. The level of physical activity was assessed using the long version of the International Physical Activity Questionnaire (IPAQ), which was validated in the local setting[19]. Participants were instructed to recall and record activities that they were engaged in the last seven days and record only the physical activity that lasted for at least 10 minutes. The long version of the IPAQ consisted of different domains such as work-related, transport-related house work-related, and sports and leisure time related physical activity. Energy utilization of all vigorous and moderated PA and walking was expressed as metabolic-equivalent-of-task (MET) min per week. The following MET values were used to analyze different categories of IPAQ data activities: Walking = 3.3 METs, Moderate activity PA = 4.0, and METs and Vigorous PA = 8.0 METs. For all domains, minutes/week were converted to Metabolic Equivalent Task (MET)/minutes/week by multiplying total minutes/week by the MET values. All the domain-specific values were then added to get the total PA score. Categorization to low, moderate, and high physical activity levels was done adhering to the IPAQ scoring protocol [20].

Anthropometric measurements. Height was measured using a microtoise steel tape and recorded to the nearest 0.5 centimeters. The subjects looked straight ahead with their head, back, and feet were touching 
the vertical support. Weight was measured without shoes on an electronic digital weighing scale to the nearest $100 \mathrm{~g}$, and the scale was calibrated after each field session against the standard weights set. The $\mathrm{BMI}$ is calculated by weight in kilograms divided by the square of the height. The classification and cutoff points used were based on the anthropometry of adult Asians. A BMI of $\leq 18.49 \mathrm{~kg} / \mathrm{m} 2$ was regarded as underweight, $18.50 \mathrm{~kg} / \mathrm{m} 2$ to $23.00 \mathrm{~kg} / \mathrm{m} 2$ as desirable, $23.01 \mathrm{~kg} / \mathrm{m} 2$ to $27.50 \mathrm{~kg} / \mathrm{m} 2$ as overweight and $\geq 27.51 \mathrm{~kg} / \mathrm{m} 2$ as obese [21].

\section{Results}

Of the 275 SOs invited for the study, 272 responded. Therefore, the response rate of SOs was $98.9 \%$. Of the 760 MAs invited, 739 responded; hence, the response rate for MAs was $97.2 \%$. Selected sociodemographic and occupational characteristics of SOs and MAs are given in Table 1. The mean ages were 44.1 (SD \pm 9.0 ) and 42.1 (SD \pm 8.7 ) years for SOs and MAs, respectively. The majority were Sinhalese in both categories. A majority of the respondents among SOs $(39.7 \% ; n=108)$ and MAs $(43.3 \% ; n=320)$ were between 30 and 39 years. 


\section{Table 1}

Sociodemographic/Economic and Occupational Characteristics of the Senior-Officers $(n=272)$ and Managerial Assistants $(n=739)$.

Variable

Age (years)

30-39

40-49

$50-60$

Gender

Female

Male

Level of education

GCE Ordinary Level passed

GCE. Advanced level passed

Technical/diploma/vocational training

University degree

Postgraduate degree

Average monthly salary (Rs)

$10000-29000$

$30000-49000$

350000

Family income (Rs)

\begin{tabular}{lllll}
$£ 20000$ & 4 & 1.5 & 32 & 4.3 \\
\hline $21000-59000$ & 160 & 58.8 & 612 & 82.8 \\
\hline $60000-99000$ & 80 & 29.4 & 72 & 9.8 \\
\hline 3100000 & 28 & 10.3 & 23 & 3.1
\end{tabular}

Occupational characteristics

Duration of service in the current workplace (years)

$£ 5$
Senior Officers

n $\%$ n

Managerial Assistants

$\%$

\begin{tabular}{llll}
108 & 39.7 & 320 & 43.3 \\
\hline 73 & 26.8 & 228 & 30.8 \\
\hline 91 & 33.5 & 191 & 25.9
\end{tabular}

$\begin{array}{llll}156 & 57.4 & 578 & 77.3 \\ 116 & 42.6 & 168 & 22.7\end{array}$

0

0

17

2.3

9

3.3

100

13.5

128

47.1

397

53.7

24

8.8

64

8.7

111

40.8

161

21.8

135

49.6

712

96.3

107

39.4

27

3.7

30

11.0

0

0

0

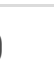




\begin{tabular}{|lllll|}
\hline $6-10$ & 64 & 23.5 & 214 & 29 \\
\hline $11-20$ & 19 & 7.1 & 40 & 5.4 \\
\hline${ }^{3} 21$ & 11 & 4 & 28 & 3.8 \\
\hline Average work hours per week (hours) & & & & \\
\hline 40 & 60 & 22.1 & 255 & 34.5 \\
\hline $41-50$ & 159 & 58.5 & 417 & 56.4 \\
\hline 351 & 53 & 19.4 & 67 & 9.1 \\
\hline Commuting distance $(\mathrm{km})$ & & & & \\
\hline £10 & 67 & 24.6 & 200 & 27.1 \\
\hline $11-20$ & 106 & 39 & 191 & 25.8 \\
\hline $21-30$ & 39 & 14.3 & 113 & 15.3 \\
\hline $31-40$ & 19 & 7 & 70 & 9.5 \\
\hline 341 & 41 & 15.1 & 165 & 22.3 \\
\hline Grade of work & & & & 30.1 \\
\hline Special grade & 58 & 21.3 & 22 & 3 \\
\hline Grade I & 89 & 32.7 & 189 & 25.6 \\
\hline Grade II & 56 & 20.6 & 305 & 41.3 \\
\hline Grade III & 69 & 25.4 & 223 & 30.5 \\
\hline
\end{tabular}

The main modality of commuting to work for SOs (59\%) was private transport and MAs (64\%) public transport. Thirty-nine-percent $(n=106)$ SOs and $25.8 \%(n=191)$ MAs reported a commuting distance between $11-20 \mathrm{Km}$. The median distance from the current residence to the current workplace was 15 $\mathrm{Km}($ range $0.25-130 \mathrm{Km}$ ) and $20 \mathrm{~km}$ (range of $0.2-131 \mathrm{Km}$ ) for SOs and MAs, respectively.

As shown in figure 2, socio-economic variations in PA levels were observed as $54.4 \%(n=148)$ seniorofficers were involved in inadequate PA, whereas among the managerial assistants, only $30.0 \%(n=222)$ were in the above category. Of the 1011 respondents, $37 \%(n=370), 56.8 \%(n=574)$, and $6.6 \%(n=67)$ were involved in low, moderate, and high PA levels based on MET scores calculated using MET mins per week.

Considering the total physical activity levels, the mean MET/mins/week was 2739.5 (SEM 159.2) and 3343.9 (SEM128) for SOs and MAs, respectively (Table 2). 


\section{Table 2}

Physical inactivity (in MET mins/day) stratified by sub-groups

\begin{tabular}{|c|c|c|c|c|}
\hline \multirow[t]{2}{*}{ Sub-group } & \multicolumn{2}{|c|}{ Senior Officers } & \multicolumn{2}{|c|}{ Managerial Assistants } \\
\hline & $\mathbf{n}$ & MET/ mins Mean ( $\pm S D)$ & $\mathbf{n}$ & MET/mins \\
\hline & & & & Mean \\
\hline & & & & $( \pm S D)$ \\
\hline
\end{tabular}

\section{Age-group (years)}

30-39

$107 \quad 2549.6$

325

3131

0.039

$( \pm 2276.8)$

$( \pm 3126.1)$

$40-49$

$73 \quad 2695$

228

3947

0.003

$( \pm 2640.2)$

$( \pm 4246.0)$

$50-60$

$91 \quad 2998.4$

$182 \quad 2970.4$

0.94

$( \pm 2968.5)$

$( \pm 2719.0)$

\section{Gender}

Male

$113 \quad 2719.8$

167

3597.8

0.0094

$( \pm 2562.5)$

$( \pm 2877.3)$

Female

$158 \quad 2753.5$

$568 \quad 3269.4$

0.08

$( \pm 2669.7)$

$( \pm 3541.7)$

\section{BMI categorization}

Normal and underweight $\quad 85 \quad 2912.6$

264

3771.6

0.031

$( \pm 2910.3)$

$( \pm 3830.7)$

Overweight

$134 \quad 2681.4$

314

3459.2

0.008

$( \pm 2436.3)$

$( \pm 3623.6)$

Obese

$52 \quad 2606.1$

$157 \quad 3167.9$

0.22

$( \pm 2618.7)$

$( \pm 3592.6)$

\section{MET based on activity}

Work-related

$271 \quad 296.4$

732

530.6

0.001

$( \pm 798.4)$

( \pm 1416.4$)$

Transport related

$272 \quad 464.4$

733

633.1

0.009

$( \pm 748.2)$

$( \pm 1223.1)$ 


\begin{tabular}{|lcllll|}
\hline Leisure and sports-related & 271 & 315.3 & 735 & 241.2 & 0.21 \\
& & $( \pm 846.4)$ & & $( \pm 732.5)$ & \\
\hline Domestic activity & 272 & 1663.9 & 735 & 1924.5 & $<.001$ \\
& & $( \pm 1746.6)$ & & $( \pm 2239.5)$ & \\
Total Physical Activity & 271 & 2739.5 & 735 & 3343.9 & 0.003 \\
& & $( \pm 2620.8)$ & & $( \pm 3445.7)$ & \\
\hline
\end{tabular}

Among SOs and MAs, $68 \%(n=69)$ and $59.9 \%(n=132)$ of the hypertensives reported a commuting distance of $\leq 20 \mathrm{Km}$, respectively. Commuting distance was positively correlated $(\mathrm{p}<0.05)$ with total transport MET among SOs and MAs.

The study revealed that the age- and sex-adjusted prevalence of hypertension was almost equal among SOs $(32.9 \%$; 95\% Cl=27.4, 38.6) and MAs (33.01\%; 95\% Cl=29.6, 36.4) (Table 3). Of the diagnosed hypertensives, $47.5 \%(n=145)$, were physically inactive/ less active and considering non-hypertensives, $34.7 \%(n=245)$ were physically inactive/ less active.

\begin{tabular}{|lccll|}
\hline \multicolumn{5}{|c|}{ Table 3 } \\
Prevalence of hypertension among the study population
\end{tabular}

After adjusting for potential confounding factors being physically inactive was associated with a higher risk of hypertension [odds ratio (OR) 1.33 [95\% $\mathrm{Cl} 1.07,1,65]$ (Table 4). Commuting distance was positively correlated $(\mathrm{p}<0.05)$ with total transport MET among SOs and MAs. After adjusting the 
commuting distance of $>20 \mathrm{~km}$ was associated with lower odds of hypertension among SOs and MAs (OR=0.713; $95 \% \mathrm{Cl} 0.4$ to 1.3 ; and $\mathrm{OR}=0.63 ; 95 \% \mathrm{Cl} 0.46$ to 0.87 ).

Table 4

Unadjusted and adjusted incidence rate ratios of Physical inactivity compared with adequate PA on hypertension.

$\begin{array}{lll}\text { Variables } & \text { Unadjusted } & \text { Adjusted } \\ & \text { OR } & \text { OR }\end{array}$

$(95 \% \mathrm{Cl})$

$(95 \% \mathrm{Cl})$

Physical Inactivity

1.37

1.33

$[1.03,1.80]$

$(1.07,1.65)$

*Adjusted for age, gender, education level, family income, body mass index, and alcohol intake

\section{Discussion}

This study mainly investigated the association between physical inactivity and hypertension and explore socio-economic variations in physical activity in government officials in Sri Lanka. The interrelationship between and physical health is not a new concept. In this era is an interrelationship between health, healthy behaviours, and social determinants has gained limelight.

The senior officers and managerial assistants were studied separately for the prevalence of hypertension and related risk-factors. They are two distinct categories socioeconomically and deemed to have a different distribution of determinants. Senior officers and managerial assistants attached to government Public Administrative offices are authorized officers to conducted administrative tasks in the country. These two populations have different job roles and responsibilities, exposing them to different determinants of ill health, especially hypertension, and therefore different prevalence of hypertension.

Physical activity /inactivity was defined be an activity level as recommended by Craig et al. IPAQ long version was used to assess the physical activity of the study population. IPAQ's long version was instrumental in assessing occupation, transportation, home-based activities, and leisure only (most commonly). The data gathered was used to assess the type, frequency, duration, and intensity of the PA [10]. This data was later converted to the Metabolic equivalent of task (MET) and quantified in MET-hours per day per week $[12,13]$. The study found that $54.4 \%(n=148)$ SOs and $30.0 \%(n=222)$ were involved in inadequate PA. Of the 1011 respondents, 37\% $(n=370), 56.8 \%(n=574)$, and $6.6 \%(n=67)$ were involved in low, moderate, and high PA levels based on MET scores calculated using MET mins per week. It should be noted that reported physical inactivity levels are likely to be an underestimate the true burden attributable to inactive lifestyles. 
The current study showed that domestic activity was the main activity mode, followed by transportrelated activity among SOs and MAs. This finding is supported by another study conducted in Sri Lanka in which they reported that the main mode of energy expenditure is domestic work[22]. Domestic activities involve housework, household maintenance, yard work, and caring for the family. Increasing active travel leads to increase physical activity. The mode of traveling to work and the health benefits are not much researched, especially in Sri Lanka. Commuting to work is defined as regular travel between place of residence and work. Sedentary behavior associated with sedentary commuting hinders physical activity and thereby leads to ill health. Commuting distance was positively correlated $(p<0.05)$ with total transport MET among SOs and MAs, meaning active travel was involved. After adjusting, commuting distance of $>20 \mathrm{~km}$ was associated with lower odds of hypertension among SOs and MAs. These findings are supported by a cross-sectional study done in India[23]. Additionally, creating low-traffic neighborhoods (LTN) is also essential in this context to improve walking and cycling [24]. This study revealed that the mode of transportation depended on the SES. However, if LTN's are implemented, this would increase public health benefits for all irrespective of the socio-economic strata.

Considering physical activity based on SES strata, it is evident that across all subgroups, there was a significant difference of physical inactivity. Educational attainment, and occupational category are indicators of the socio-economic status of an individual, a key determinant of health,[25, 26] and helps explain senior-officers' and managerial-assistants' physical activity patterns. The SOS and MAs differed in educational level and monthly family income $(p<0.05)$. The MAs reported a lower physical inactivity level (30\%) than the SOs (54\%) ( $p=0.05)$. The mean MET/mins/week was 2739.5 (SEM 159.2) and 3343.9 (SEM128) for SOs and MAs, respectively. These findings are consistent with those of other studies, showing variations in physical inactivity across socio-economic status (SES) strata[27]. A study conducted in Sri Lanka which reports that high level of education and older males have less physical activity, supports the findings of the current study[28]. However, this study revealed that MAs, as opposed to SOs, reported significantly $(P<0.005)$ higher MET-based activity levels related to work, transport, and domestic activities. Senior officers travel in private vehicles, are more involved with meetings and paperwork, and work long working hours, leading to a sedentary lifestyle. The observed inverse relationship between age and physical inactivity is consistent with studies conducted elsewhere[29]. A possible explanation for this finding is that younger people opt for healthy habits and that with increasing age, employees become more sedentary.

Interestingly leisure and sports-related MET was higher among the SOs ( $p>0.05)$. It could be that perceived lack of activity prompts the SOs to engage in sports-related activity when free. However, compared to other domains, leisure-time physical activity was low among both SOs (315 (SEM 846)) and MAs (241 (SEM 733)) MET/mins/week, and this is similar to studies done elsewhere[27, 30]. In the Mexico City Diabetes Study, a cohort study, they reported low levels of leisure-time physical activity levels (336 MET/ mins/ week)[30]. Despite the current knowledge of physical activity promoting an individual's health, the practices among sedentary workers are different. The rapid socio-economic development is leading to a more sedentary type of lifestyle. 
The present study carried out among administrators (SOs and MAs) confirms previously reported trends in the prevalence of hypertension and physical inactivity in Sri Lanka. The age and sex-adjusted prevalence of hypertension among 30- 60 years SOs and MAs attached to the above offices were 32.9 per hundred population with a $95 \% \mathrm{Cl}$ of 27.4 to 38.6 and 33.01 per hundred population with a $95 \% \mathrm{Cl}$ of 29.6 to 36.4 respectively. The observed differences between the two percentages among SOs and MAs were not statistically significant ( $p>0.05)$. Of the SOs $63.6 \%(n=173)$ were normotensives and $4.0 \%(n=11)$ were pre-hypertensives while $21.3 \%(n=58), 1.5 \%(n=4)$, and $0.7 \%(n=2)$ were in the hypertension stage I, stage II and in the isolated systolic categories respectively. Considering MAs 63.5\% ( $n=469)$ were normotensives and $7.2 \%(n=53)$ were pre-hypertensives, while $19.9 \%(n=147), 1 \%(n=7)$, and $1.9 \%(n=$ 14) were in the hypertension stage $\mathrm{I}$, stage II and in the isolated systolic categories respectively. Of the hypertensive SOs and MAs, 52.3\% $(n=46)$ and 35\% $(n=76)$ were unaware they had hypertension, respectively. Of the patients diagnosed and on treatment for hypertension, $68.6 \%(n=24)$ of SOs and $43 \%$ $(n=49)$ of MAs had controlled hypertension.

Of the diagnosed hypertensives, $44.7 \%(n=106)$, and $49.4 \%(n=117)$ reported a low and moderate PA and considering non-hypertensives, $35.9 \%(n=278), 57.5 \%(n=445)$ reported a low and moderate activity levels respectively. After adjusting for potential confounding factors (age, gender, education level, family income, body mass index, and alcohol intake), being physically inactive was associated with a higher risk of hypertension [odds ratio (OR) 1.33 [95\% Cl 1.07, 1,65]. The physically inactive participants had 33\% greater odds of having hypertension than the physically active participants. This is similar to the findings from a cohort study involving 2,282 participants, who were followed for 20 years, which reported accumulating $<1 \mathrm{MET} / \mathrm{min} /$ week of occupational moderate to vigorous physical activity was associated with a $47 \%$ higher risk of hypertension (HR 1.47, CI 95\% 1.13, 1.90) and accumulating < $1 \mathrm{MET} / \mathrm{min} /$ week of leisure moderate to vigorous physical activity was associated with $29 \%$ higher risk of hypertension $1.29(1.01,1.66)$. There are many aetiological factors behind the development of hypertension. Studies report that it may be through reducing body weight, reducing psychological stress, improving insulin sensitivity, and reducing sympathetic activity [31].

The study is not without limitations. As this study was conducted in the government administration offices in the Colombo district, the results may not apply to all administrative employees in the country, which is considered a limitation of the study. Physical activity was based on self-reports which required a 7-day recall. This might not necessarily reflect accurate physical activity levels across lifespan. Recall bias and reporting socially desirable practice may have played a role in bias towards null. Additionally, although we controlled for all the known confounders, the residual confounders may exist. The study identified physical inactivity as a correlate of hypertension through a cross-sectional comparative study design. This precluded the assessment of the temporal relationship between hypertension and salt.

\section{Conclusions And Recommendations}

Our findings suggest that physical inactivity in employees is alarmingly high. Low physical activity levels were observed among the hypertensive individuals compared with the non-hypertensive participants. 
Physical inactivity is an important independent contributor to hypertension among employees. The present study adds to the evidence of wider influencing factors related to physical inactivity as socioeconomic variations in PA levels existed. The socio-economic disparities observed in physical activity levels highlight the importance of considering social differences to ensure successful and equitable implementation of programs to prevent hypertension. Higher commuting distance is positively correlated with total transport MET and is associated with lower odds of hypertension among SOs and MAs. This implies that active travel increases physical activity and thereby results in lower odds of having hypertension. This is important because promoting active travel is important, which could be done by creating a conducive environment such as low traffic neighborhoods. Therefore policies and environment to promote and at least 15-30 minuets of physical activity are necessary to avert the premature deaths due to chronic illnesses such as hypertension.

\section{Abbreviations}

IPAQ- International Physical Activity Questionnaire

MAs- Managerial Assistants

MET-Metabolic-Equivalent-of-Task

PA-Physical activity

SES- Socio-economic status

SOS-Senior officers

WHO-World Health Organization

\section{Declarations}

\section{Ethics approval and consent to participate:}

Informed written consent was obtained from the participants by giving the necessary forms immediately before recruitment. Ethical clearance for the study was obtained from the Ethical Review Committee of the Faculty of Medicine, University of Colombo, Sri Lanka. All methods were performed in accordance with the relevant guidelines and regulations, by the ethical review committee which granted ethical clearance for the study.

\section{Consent for publication}

Not Applicable 


\section{Availability of data and material}

The datasets generated and/or analysed during the current study are not publicly available due to limitations of ethical approval involving the patient data and anonymity but are available from the corresponding author on reasonable request.

\section{Competing interests}

The funding agency had no role in the design, analysis, or interpretation of data, writing of the report, or the decision to submit the article for publication. The authors were entirely independent of the funding agency in conducting the research. The authors declare that they have no conflicts of interest. All authors have access to the data analyzed in the study and take responsibility for the integrity of the data and the accuracy of the analysis.

\section{Funding}

Funding for this study was provided by the Non-communicable Disease Unit Ministry of Health, Sri Lanka.

\section{Authors' contributions}

AUG and RdeAS designed the analysis plan. RdeAS supervised the project. AUG performed the statistical analyses and wrote the first draft of the manuscript. All authors contributed to the interpretation of the results and the revision of the manuscript. RdeAS is the guarantor.

\section{Acknowledgments}

The authors gratefully acknowledge the time and effort given by all the participants to make this study a success.

\section{References}

1. Blair SN: Physical inactivity: the biggest public health problem of the 21st century. British journal of sports medicine 2009, 43(1):1-2.

2. Kahn EB, Ramsey LT, Brownson RC, Heath GW, Howze EH, Powell KE, Stone EJ, Rajab MW, Corso P: The effectiveness of interventions to increase physical activity: A systematic review1, 2 1The names and affiliations of the Task Force members are listed in the front of this supplement and at www. thecommunityguide. org. 2Address correspondence and reprint requests to: Peter A. Briss, MD, Community Guide Branch, Centers for Disease Control and Prevention, 4770 Buford Highway, MS- 
K73, Atlanta, GA 30341. E-mail: PBriss@ cdc. gov. American journal of preventive medicine 2002, 22(4):73-107.

3. Lee I-M, Shiroma EJ, Lobelo F, Puska P, Blair SN, Katzmarzyk PT, Group LPASW: Effect of physical inactivity on major non-communicable diseases worldwide: an analysis of burden of disease and life expectancy. The lancet 2012, 380(9838):219-229.

4. WHO M: Global health observatory data repository. World Health Organization 2015.

5. Talaei M, Rabiei K, Talaei Z, Amiri N, Zolfaghari B, Kabiri P, Sarrafzadegan N: Physical activity, sex, and socioeconomic status: A population based study. ARYA Atheroscler 2013, 9(1):51-60.

6. World Health Organization: Global recommendations on physical activity for health. In: 1Exercise 2 Life style 3 Health promotion 4Chronic disease - prevention and control 5National health programs. Edited by WHO. Geneva, Switzerland WHO; 2010.

7. Ishikawa-Takata $\mathrm{K}$, Ohta $\mathrm{T}$, Tanaka $\mathrm{H}$ : How much exercise is required to reduce blood pressure in essential hypertensives: a dose-response study*. American Journal of Hypertension 2003, 16(8):629-633.

8. Guthold R, Ono T, Strong KL, Chatterii S, Morabia A: Worldwide Variability in Physical Inactivity: A 51Country Survey. American Journal of Preventive Medicine 2008, 34(6):486-494.

9. The Lancet Public H: Time to tackle the physical activity gender gap. The Lancet Public Health 2019, 4(8):e360.

10. Elin Bandmann: Physical activity questionnaires- A critical review of methods used in validity and reproducibility studies. In., edn. GIH - THE SWEDISH SCHOOL OF SPORT AND HEALTH SCIENCES; 2008.

11. Craig CL, Marshall AL, Sjöström M, Bauman AE, Booth ML, Ainsworth BE, Pratt M, Ekelund U, Yngve A, Sallis JF: International physical activity questionnaire: 12-country reliability and validity. Medicine \& science in sports \& exercise 2003, 35(8):1381-1395.

12. Jetté $M$, Sidney K, Blümchen G: Metabolic equivalents (METS) in exercise testing, exercise prescription, and evaluation of functional capacity. Clinical cardiology 1990, 13(8):555-565.

13. Mendes MdA, da Silva I, Ramires V, Reichert F, Martins R, Ferreira R, Tomasi E: Metabolic equivalent of task (METs) thresholds as an indicator of physical activity intensity. PloS one 2018, 13(7):e0200701-e0200701.

14. Gamage AU, Seneviratne RDA: Perceived Job Stress and Presence of Hypertension Among Administrative Officers in Sri Lanka. Asia Pacific Journal of Public Health 2015, 28(1_suppl):41S$52 S$.

15. Gamage AU, De Alwis Seneviratne R, Hanna FS: Salt intake, blood pressure, and socioeconomic disparities among government employees in Sri Lanka: a cross-sectional study. J Public Health Policy 2017, 38(3):327-344.

16. Pickering TG, Hall JE, Appel LJ, Falkner BE, Graves J, Hill MN, Jones DW, Kurtz T, Sheps SG, Roccella EJ: Recommendations for blood pressure measurement in humans and experimental animals: part 
1: blood pressure measurement in humans: a statement for professionals from the Subcommittee of Professional and Public Education of the American Heart Association Council on High Blood Pressure Research. Hypertension 2005, 45(1):142-161.

17. Ogedegbe G, Pickering T: Principles and techniques of blood pressure measurement. Cardiol Clin 2010, 28(4):571-586.

18. Chobanian AV, Bakris GL, Black HR, Cushman WC, Green LA, Izzo Jr JL, Jones DW, Materson BJ, Oparil S, Wright Jr JT: Seventh report of the joint national committee on prevention, detection, evaluation, and treatment of high blood pressure. hypertension 2003, 42(6):1206-1252.

19. Karunapema R: Evaluation of the effectiveness of a lifestyle intervention in primary prevention of diabetes among adults with impaired fasting glucose from a rural area in Gampaha District, Sri Lanka. 2007.

20. Forde C: Scoring the International Physical Activity Questionnaire (IPAQ) Exercise Prescription for the Prevention and Treatment of Disease, 2005.

21. Shiwaku K AE, Enkhmaa B, Kitajima K, Yamane Y.: Appropriate BMI for Asian populations . The Lancet 2004, 363(9414):157-163.

22. De Silva Weliange S, Fernando D, Gunatilake J: Pattern of Physical Activity Among Sri Lankan Adults in the District of Colombo. Asia Pacific Journal of Public Health 2016, 28(8):725-736.

23. Millett C, Agrawal S, Sullivan R, Vaz M, Kurpad A, Bharathi AV, Prabhakaran D, Reddy KS, Kinra S, Smith GD et al: Associations between active travel to work and overweight, hypertension, and diabetes in India: a cross-sectional study. PLoS medicine 2013, 10(6):e1001459.

24. Mason L: Low-traffic neighbourhoods - what's not to like? Perspect Public Health 2021, 141(2):70-71.

25. Ji C, Kandala N-B, Cappuccio FP: Spatial variation of salt intake in Britain and association with socioeconomic status. BMJ Open 2013, 3(1).

26. Marmot MG: Understanding social inequalities in health. Perspect Biol Med 2003, 46(3 Suppl):S9-23.

27. Medina C, Janssen I, Campos I, Barquera S: Physical inactivity prevalence and trends among Mexican adults: results from the National Health and Nutrition Survey (ENSANUT) 2006 and 2012. BMC Public Health 2013, 13(1):1063.

28. Karunanayake AL, Senaratne CD, Stathi A: A descriptive cross sectional study comparing barriers and determinants of physical activity of Sri Lankan middle aged and older adults. PLOS ONE 2020, 15(5):e0232956.

29. Yan L, Bi Z, Tang J, Wang L, Yang Q, Guo X, Cogswell ME, Zhang X, Hong Y, Engelgau M et al: Relationships Between Blood Pressure and 24-Hour Urinary Excretion of Sodium and Potassium by Body Mass Index Status in Chinese Adults. J Clin Hypertens (Greenwich) 2015, 17(12):916-925.

30. Medina C, Janssen I, Barquera S, Bautista-Arredondo S, González ME, González C: Occupational and leisure time physical inactivity and the risk of type II diabetes and hypertension among Mexican adults: A prospective cohort study. Scientific Reports 2018, 8(1):5399. 
31. Diaz KM, Shimbo D: Physical activity and the prevention of hypertension. Current hypertension reports 2013, 15(6):659-668.

\section{Figures}

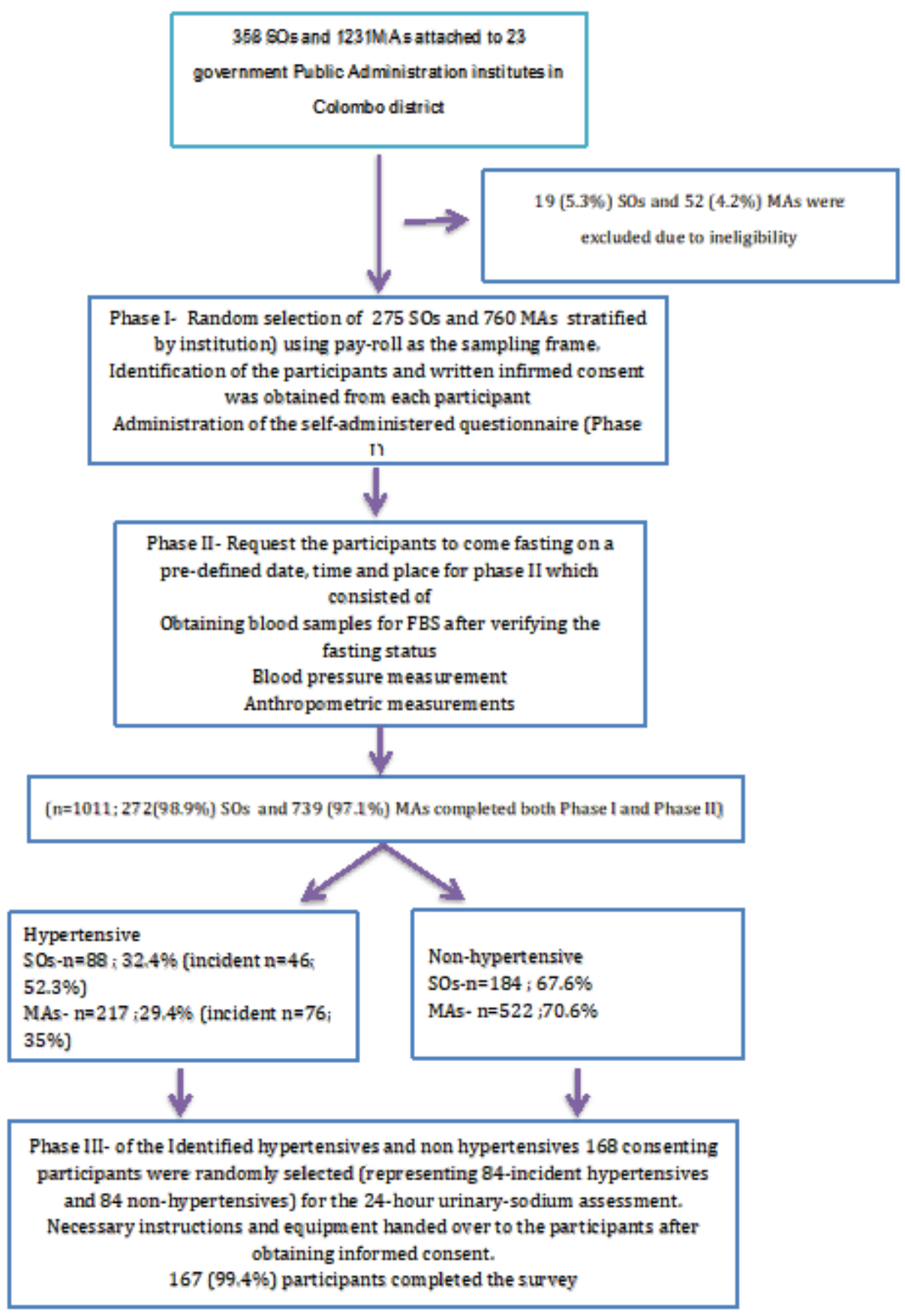

Figure 1

Flow of individuals through the study 


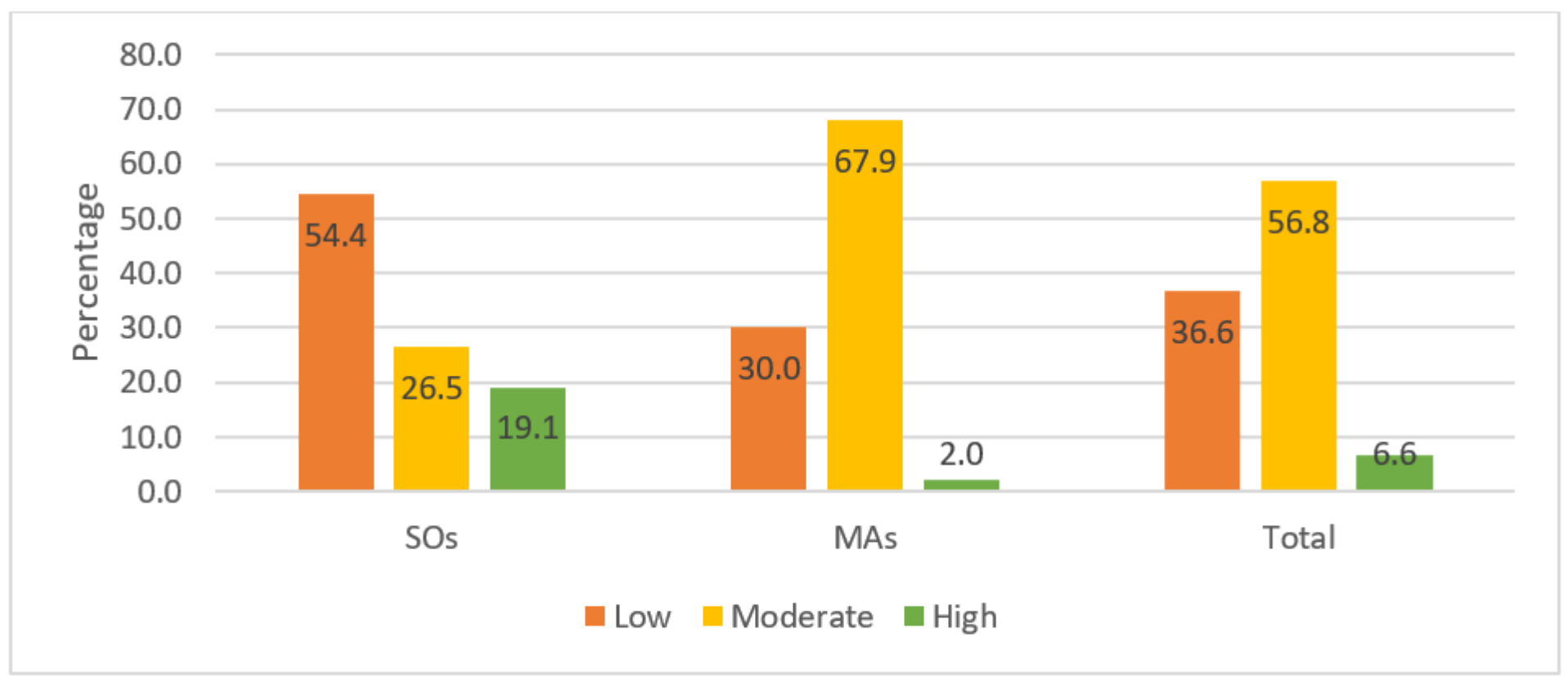

Figure 2

Levels of Physical Inactivity in the study population 